\title{
Historical Inequality and Intergenerational Educational Mobility: The Dynamics of Change in Rural Punjab
}

\section{Ali Cheema* and Muhammad Farooq Naseer ${ }^{* *}$}

\begin{abstract}
We analyze educational attainment over three generations in rural Punjab, Pakistan, to determine if the fruits of post-independence development have translated into comparable rates of educational and social opportunities for all strata in the village economy. We show that the differences in class status institutionalized at the time of colonial village settlement lead to a sustained divergence in the rate of intergenerational educational mobility, with limited mobility for nonproprietary and marginalized groups compared to proprietary groups. Inter-class differences in the rate of mobility are higher in proprietary landed estates where the colonial state had concentrated land rights and governance in the hands of landowners compared to crown estates that had a more egalitarian arrangement of land rights and governance. We find that the divergence in inter-class mobility is worrying, so much so that the current generation of marginalized households appears to have fallen a generation behind in terms of educational attainment, even though it resides in the same villages as the proprietary households.
\end{abstract}

Keywords: Inequality, education, development, Pakistan.

JEL classification: I21, I25.

\section{Introduction}

This paper measures the extent of intergenerational persistence in educational mobility across propertied and nonpropertied social groups in rural Punjab. Differences in mobility across social groups would imply persisting or widening inequality in opportunities across groups. Inequality in opportunities across groups in society is important as differences in opportunity, if they exist, imply a lopsided rise in fortunes and worsening long-run inequality. Thus, measuring intergenerational

\footnotetext{
* Associate Professor of Economics, Lahore University of Management Sciences, Senior Research Fellow, Institute of Development and Economic Alternatives, and a Fellow, Center of Economic Research in Pakistan.

** Assistant Professor of Economics, Lahore University of Management Sciences, Pakistan
} 
mobility is important to gauge the economic inequality across social groups. This is because measures of "intergenerational mobility are intrinsically connected to the extent of economic inequality in a society" (Azam \& Bhatt, 2012, p. 2). This paper provides rigorous evidence on the long-run inequality in opportunities in rural Punjab, which we hope will stimulate a debate on the acceptable levels of long-run inequality that the Pakistani polity is willing to tolerate.

Rural Sargodha provides an excellent context in which to analyze intergenerational mobility for two reasons. First, colonial village settlements in this area created deep social divisions where ownership and control of agricultural and residential land and village common property were assigned to families belonging to specific quoms (lineage groups) (Nelson, 2002; Rouse, 1988; Ahmad, 1977; Macnabb, 1934; Leigh, 1917). This stratified the village society into propertied and nonpropertied quoms and families, where nonpropertied quoms were typically associated with poor economic and social outcomes. This institutional context allows us to analyze the relationship between historic inequality and intergenerational mobility, which has not been possible in many contexts because of a paucity of data. Specially, we ask whether persistence in educational mobility is positively correlated with belonging to a historically propertied or nonpropertied quom.

Second, rural Sargodha has undergone massive structural changes in the last 130 odd years that have transformed it from a low-productivity pastoral economy to a highly productive agrarian economy (Agnihotri, 1996; Ali, 1988; Pray, 1984; Wace, 1933). This context enables us to ask whether the transformation has been able to reduce the historic inequality of opportunities and catalyze intergenerational mobility across social groups. Low rates of mobility across social groups in central Punjab would be extremely worrying because they would imply that the problem is likely to be far worse in the more stagnant agrarian regions of western Punjab and rural Sindh. Providing evidence on this question is also important as the literature is not clear whether positive changes in performance and structural change catalyze equality of opportunities (Banerjee \& Duflo, 2003) or whether historic inequality in opportunities persists in the face of agrarian transformations.

The issue of intergenerational mobility has received less empirical attention in the developing country context largely because of the paucity of suitable data. Azam and Bhatt (2012) argue that existing studies on developing countries (see, for instance, Jalan \& Murgai, 2008; Maitra \& 
Sharma, 2009; Hnatkovska, Lahiri, \& Paul, 2012) tend to suffer from biases related to the use of nonrepresentative samples as they rely on co-residence conditions within cross-sectional data to identify father-son pairs. We are able to address this issue by constructing a primary dataset that is not limited to co-resident household members.

We contribute to the literature on intergenerational mobility by providing micro-evidence on the relationship between historic inequality and intergenerational mobility-an under-researched area in the literature. While there is a burgeoning body of literature on the consequences of inequality for growth, health, and education, our understanding of the association between historic inequality and intergenerational mobility remains limited. We hope that the evidence presented here will provide valuable insights into this issue.

Additionally, this paper makes the following important contributions to the literature on the Pakistan economy. First, it provides rigorous evidence on the extent of intergenerational mobility in educational outcomes in rural Punjab and shows how this mobility has changed over the long run. This evidence will inform policymakers about the overall levels of mobility in rural Punjab, and ask whether it is an area that should concern policymakers by comparing it with findings from India. Second, we provide evidence on differential patterns of education mobility across propertied and nonpropertied groups. We hope that the evidence on intergenerational educational deficits across social groups will improve the understanding of policymakers mandated to operationalize Article 25-A of the Constitution ${ }^{1}$ - which pertains to a child's right to education-and help them target their efforts better.

We find evidence of increasing intergenerational mobility in educational attainment across three generations of rural males in district Sargodha. However, we also find significant differences in mobility between historically propertied and nonpropertied groups, with the former experiencing far less long-run mobility. This indicates the worsening longrun equality of opportunities for households whose families were at the bottom of the village social hierarchy during the colonial period. It also suggests that the agrarian transformation in the district has resulted in a lopsided rise in fortunes.

1 Article 25A (The Constitution of the Islamic Republic of Pakistan, 1973) states: "Right to education. ...The State shall provide free and compulsory education to all children of the age of five to sixteen years in such manner as may be determined by law.” 
The paper provides two stark findings on intergenerational education mobility. First, while impressive gains have been made by the propertied in terms of school transitions, households at the bottom of the historic social hierarchy continue to have extremely low rates of transition to school in spite of increased provision of schools in the district's villages. The outcome is that households whose ancestors were at the bottom of the village hierarchy have fallen a generation behind in terms of educational attainment compared to groups at the top and in the middle.

What is extremely worrying is that a significant proportion of households in the nonpropertied group have had zero change in educational attainment across three generations. The fact that this stagnation is occurring in villages with schools suggests that it is these households' demand for education that is the most serious challenge to the government's stated aim of universalizing education.

The paper is organized as follows. Section 2 describes the data and the social stratification and outcome measures used. Section 3 outlines our empirical strategy and presents the regression results for intergenerational mobility in rural Sargodha and across historically propertied and nonpropertied groups. Section 4 provides estimates of transitions to school. Section 5 analyzes educational mobility using quantile plots. Section 6 presents some conclusions.

\section{Data and Measures}

We use data from the Sargodha Village and Household Survey (SVHS) - a district-representative primary survey of rural households designed and constructed by Cheema, Mohmand, and Naseer in 2007/08. Sargodha is appropriate for our purposes as it is neither an underdeveloped district nor is it one of the more highly developed districts in the province. The SVHS is a representative survey of a random sample of households in 35 randomly drawn villages in the district. The survey was conducted between November 2007 and March 2008, and collected detailed household- and member-level information on education, historical quom status, occupation, marital status, land and family history, wealth, household assets and expenditures, demographics, social capital, and civic and political engagement. In addition, it collated information on the education, occupation, and land ownership of the household head as well as his father and sons. 
A multistage stratified random sampling technique was adopted for this survey. The 35 sample villages were randomly selected based on the 1998 Population Census listing of all revenue villages (mouazzas) in Sargodha. Villages were first stratified by the type of initial colonial settlement using databases of misl haqiats ${ }^{2}$ and colonial inspection reports conducted by British colonial officers during 1915-1920. ${ }^{3}$

In the first stage, a complete mapping and census of all households was carried out for each sample (revenue) village by a team of professional surveyors. The census form contained several questions on the economic and demographic attributes of each household, such as its landholdings, type of residential structure, and the household head's age and quom. Along with this, a detailed community survey was conducted and a physical mapping exercise carried out for each village. In the second stage, a random quom-stratified household sample was drawn for each village based on the household census data.

There are two major advantages to using the SVHS data ${ }^{4}$ to study intergenerational education mobility over and above the standard largescale Pakistani household income and expenditure survey data. First, the SVHS provides intergenerational data on the household head's father and sons irrespective of whether they are co-residents; this helps mitigate sample selection issues associated with identifying father-son pairs using the co-residence condition. Second, the SVHS contains data on actual years of schooling rather than the level of schooling completed, and therefore avoids the discontinuities associated with the use of categorical data on educational attainment.

\subsection{Historic Quom-Based Social Stratification}

As our interest is in the historical social position of each family, we use the colonial classification ${ }^{5}$ of lineage groups in Sargodha to categorize households into historically zamindar6 (landholding) quoms located at the top of the rural social hierarchy, artisanal quoms in the middle, and historically depressed 7 quoms at the bottom. The latter two belong to the

\footnotetext{
${ }^{2}$ The village record of rights.

${ }^{3}$ This database was constructed from the district of Sargodha revenue archive by the authors in collaboration with Dr Shandana Mohmand of the Institute of Development Studies.

${ }^{4}$ Azam and Bhatt (2012) find similar advantages associated with the Human Development Survey of India, 2005.

${ }^{5}$ The classification is given in detail in the Sargodha district gazetteers (various issues).

${ }^{6}$ Zamindar quoms comprise both landowners and land cultivators.

${ }^{7}$ Colonial sources classify this group as menials and place them at the bottom of the social hierarchy.
} 
historically nonpropertied population and the zamindar quom constitutes the propertied group.

We can identify the historical social position of existing households by mapping their quom status enumerated through the household census against the colonial classification of the three main social groups based on information given in the district gazetteers and the database of colonial inspection reports. Given that the historical quom status of the household is prone to reporting bias, the information collected on each household through the census was triangulated with key local respondents as well as through a community verification exercise. Inconsistencies in information between these sources were resolved through interviews with village elders.

\subsection{Preferred Outcome Measure}

We use educational attainment as the proxy for intergenerational economic mobility instead of earnings or wealth as it is less likely to be prone to serious errors of measurement. It is also less likely to suffer from lifecycle biases as most individuals complete their education by the second decade of their lives. More importantly, the literature on developing countries and Pakistan shows that this measure is highly correlated with higher earnings and wealth, movements out of poverty, better health, higher skills, and better labor market outcomes (Arif, 2003, 2006; Black \& Devereux, 2011). Finally, this measure has assumed considerable importance in its own right in the Pakistani context after the recent passage of Article 25-A of the country's Constitution.

\section{Empirical Strategy and Results}

We start by providing evidence on the extent of intergenerational mobility in rural Sargodha across three generations in a family. The regression model we estimate is:

$$
e d u c_{i, f}=\alpha+\beta e d u c_{i-1, h}+u_{h}, i \in\{2,3\}, f=1,2, \ldots 417
$$

where subscript $f$ denotes the family, $i$ denotes the generation, and $e d u c_{i, f}$ denotes the years of schooling of generation $i$ in family $f . \beta$ is the coefficient of interest and measures persistence in educational attainment for generation $i$, where higher values imply greater persistence. Alternatively, $(1-\beta)$ is a measure of intergenerational mobility across 
generations with lower values indicating less mobility. We have reported the results for both these measures.

In order to ensure balance in our panel, we define the following three generational cohorts for each of the 417 households in our sample:

- Generation 1 ("grandfather"): individuals aged 65+ years in the survey year 2008

- Generation 2 ("father"): individuals aged 40-65 years in 2008

- Generation 3 ("son"): individuals aged 20-40 years in 2008

We estimate equation (1) above for successive pairs of these generational cohorts. Table 1 reports the results for the two pairs of generational cohorts. It shows that the father's education in each generational pair has an economically and statistically significant effect on the child's years of schooling. It also shows a pronounced decline in persistence across generations, with the estimated coefficient $\beta$ declining from 0.875 for the grandfather-father pair to 0.413 for the father-son pair. This provides evidence for increased educational mobility in rural Sargodha-an expected trend that is consistent with the gains in educational attainment reported through aggregate data.

Table 1: Intergenerational educational mobility in Sargodha

\begin{tabular}{lcc}
\hline & \multicolumn{2}{c}{ Dependent variable } \\
\cline { 2 - 3 } & $\begin{array}{c}\text { Father's years of } \\
\text { schooling }\end{array}$ & $\begin{array}{c}\text { Eldest son's years of } \\
\text { schooling }\end{array}$ \\
\hline Grandfather's/father's years of & $0.875^{* *}$ & $0.413^{* * *}$ \\
schooling & $(0.074)$ & $(0.04)$ \\
Mobility & 0.125 & 0.587 \\
Observations & 417 & 417 \\
R-squared & 0.154 & 0.204 \\
\hline
\end{tabular}

Note: Standard errors clustered at the village level reported in parentheses. ${ }^{* *}=1$ percent significance level, ${ }^{* *}=5$ percent significance level.

Source: Sargodha Village and Household Survey (2007/08).

The real question, which is central to this paper, is whether there is a significant difference in the degree of intergenerational mobility across the three social groups that comprised the historical village hierarchy in 
rural Sargodha. We address this question by estimating the following regression model:

$$
e^{d u c_{i f, q}}=\alpha+\beta e d u c_{i-1, h, q}+u_{h, q}, i \in\{2,3\}, f=1,2, \ldots 417
$$

In equation (2), $q$ is the quom of the household head's family and corresponds to zamindar, artisanal, or historically depressed quoms (see Section 2.1). The variable $e d u c_{i, f, q}$ denotes the years of schooling of generation $i$ in family $f$ and quom $q$. We estimate this equation for each of the three quoms and for the two pairs of successive generational cohorts.

Table 2 shows that there is a negative trend in the value of the $\beta$ coefficient across the generational pairs. The coefficient on the father and grandfather's education term is economically and statistically significant for successive generational pairs across all three quoms. However, we find much higher rates of educational mobility among zamindars than artisans and historically depressed quoms. While the estimated coefficient of $\beta$ declines sharply from 0.802 for the grandfather-father pair to 0.279 for the father-son pair in the case of zamindar quoms, its decline is far less pronounced in the case of artisanal and historically depressed quoms.

This evidence points to significant differences in the degree of intergenerational mobility across social groups, with historically nonpropertied groups experiencing far less long-run mobility in educational attainment than propertied groups. This indicates worsening long-run inequality of opportunities among the propertied and nonpropertied groups in rural Sargodha, and suggests that the agrarian transformation in the district is causing a lopsided rise in fortunes between these social groups. 
Table 2: Intergenerational educational mobility by quom in Sargodha

\begin{tabular}{lcc}
\hline & \multicolumn{2}{c}{ Dependent variable } \\
\cline { 2 - 3 } & $\begin{array}{c}\text { Father's years of } \\
\text { schooling }\end{array}$ & $\begin{array}{c}\text { Eldest son's years of } \\
\text { schooling }\end{array}$ \\
\hline Grandfather's/father's years of & $0.802^{* * *}$ & $0.279^{* * *}$ \\
schooling & $(0.087)$ & $(0.061)$ \\
Mobility & 0.198 & 0.721 \\
Observations & 228 & 228 \\
R-squared & 0.157 & 0.120 \\
\hline & \multicolumn{2}{c}{ Artisanal quom } \\
Grandfather's/father's years of & $0.910^{* * *}$ & $0.506^{* * *}$ \\
schooling & $(0.149)$ & $(0.090)$ \\
& 0.090 & 0.494 \\
Mobility & 79 & 79 \\
Observations & 0.167 & 0.294 \\
R-squared & Historically depressed & quom \\
\hline & 0.680 & $0.525^{* * *}$ \\
Grandfather's/father's years of & & $(0.094)$ \\
schooling & $(0.459)$ & 0.475 \\
Mobility & 0.320 & 108 \\
Observations & 108 & 0.179 \\
R-squared & 0.058 & \\
\hline
\end{tabular}

Note: Standard errors clustered at the village level reported in parentheses. ${ }^{* * *}=1$ percent significance level.

Source: Sargodha Village and Household Survey (2007/08).

How does the difference in educational mobility between historically propertied and nonpropertied groups in Pakistan compare with the differences in mobility among higher, intermediate, and lower caste $^{8}$ groups in India? The comparison is instructive, given the two countries' shared historical and colonial experience.

\footnotetext{
${ }^{8}$ In rural India, historical caste status defined the historical social status of individuals and their families (Munshi \& Rosenzweig, 2009; Rosenzweig \& Munshi, 2006; Azam \& Bhatt, 2012). It is unclear to whether the correspondence between caste and proprietary status in the Hindu-majority
} 
Tables 3 and 4 report Azam and Bhatt's (2012) results for the pattern of intergenerational education mobility for four different social groups-high castes, Other Backward Castes (OBCs), Scheduled Castes, and Muslims-in India. We compare our results (Table 2) and theirs (Tables 3 and 4) in order to put our findings on differences in intergenerational mobility across social groups into regional context.

Tables 3 and 4 report their findings for sons who were born during the periods 1961-65 or 1981-85 as these correspond broadly to the birth period of our father-son generational pair. The Azam and Bhatt (2012) study is useful because it uses a similar regression model to measure intergenerational mobility. However, since this comparison is not based on a well-specified cross-country regression model, its results should, at best, be seen as providing only indicative evidence.

Table 3: Intergenerational educational mobility by social group in India

(I)

\begin{tabular}{lcc}
\hline Dependent variable: Son's years of schooling & \multicolumn{2}{c}{ Son's birth cohort } \\
\hline & $1961-65$ & $1981-85$ \\
& Higher Hindu castes \\
Grandfather's/father's years of schooling & $0.510^{* * *}$ & $0.406^{* * *}$ \\
& $(0.025)$ & $(0.021)$ \\
Mobility & 0.490 & 0.594 \\
Observations & 1,474 & 2,018 \\
R-squared & 0.271 & 0.271 \\
\hline & \multicolumn{3}{c}{ OBCs } \\
Grandfather's/father's years of schooling & $0.645^{* * *}$ & $0.487 * * *$ \\
& $(0.033)$ & $(0.028)$ \\
Mobility & 0.355 & 0.513 \\
Observations & 2,027 & 3,114 \\
R-squared & 0.217 & 0.267 \\
\hline
\end{tabular}

Note: ${ }^{* * *}=1$ percent significance level.

Source: Azam and Bhatt (2012).

A comparison of Tables 2, 3, and 4 shows that the father-son pair in the zamindar quom of Sargodha has a much higher mobility coefficient

districts of India was as tight as that between the proprietary and social status of families in the villages of rural Punjab (Bayley, 2001; Ahmad, 1977; Rouse, 1988). 
(0.721) than those reported for higher-caste Hindus. We also find that the mobility coefficients among father-son pairs in the artisan and the historically depressed quoms are worse than those reported for the Scheduled Castes with sons in the 1981-85 birth cohort. This suggests that the mobility experience of households in Sargodha is in stark contrast to the finding for India that "there has been an improvement in mobility across social groups, especially at the lower end of the educational distribution" (Azam \& Bhatt, 2012, p. 33).

Table 4: Intergenerational educational mobility by social group in India (II)

\begin{tabular}{lcc}
\hline Dependent variable: Son's years of schooling & \multicolumn{2}{c}{ Son's birth cohort } \\
& \multicolumn{1}{c}{ 1961-65 } & 1981-85 \\
& \multicolumn{1}{c}{ Scheduled Castes/Tribes } \\
Grandfather's/father's years of schooling & $0.685^{* * *}$ & $0.467^{* * *}$ \\
& $(0.043)$ & $(0.027)$ \\
Mobility & 0.315 & 0.533 \\
Observations & 1,667 & 2,622 \\
R-squared & 0.207 & 0.179 \\
\hline & \multicolumn{2}{c}{ Muslims } \\
Grandfather's/father's years of schooling & $0.622^{* * *}$ & $0.571^{* * *}$ \\
& $(0.051)$ & $(0.026)$ \\
Mobility & 0.378 & 0.429 \\
Observations & 628 & 1,316 \\
R-squared & 0.217 & 0.308 \\
\hline
\end{tabular}

Note: ${ }^{* * *}=1$ percent significance level.

Source: Azam and Bhatt (2012).

\section{School Transitions}

Next, we analyze the question of education mobility as if it were a discrete event in the lives of these rural households. For this, we code anyone who went to school and received some education as distinct from those household members who did not receive any formal schooling and never went to school. The idea is to distinguish the act of enrolling in school from the years of completed schooling, the former acting more as an observable/behavioral signal of intent whereas the latter may be a composite outcome influenced by multiple factors. 
Table 5 reports data on households where the next generation received some education as a proportion of all those households in which members of the prior generation did not go to school. Thus, the statistics reported in columns 1-3 of the table present the proportion of upwardly mobile households where mobility is measured by the decision of unschooled parents to send their next generation to school. This analysis presents a lower-bound estimate of the degree of educational mobility among the families belonging to the three quoms.

Table 5: Generational transition to schooling by quom

\begin{tabular}{|c|c|c|c|c|c|c|}
\hline \multirow[b]{2}{*}{ Pair } & \multirow[b]{2}{*}{ Zamindar } & \multirow[b]{2}{*}{ Artisan } & \multirow[b]{2}{*}{$\begin{array}{c}\text { Historically } \\
\text { depressed } \\
\text { quom (HDQ) }\end{array}$} & \multicolumn{3}{|c|}{ Differences in means } \\
\hline & & & & $\begin{array}{c}\text { (i) } \\
\text { Zamindar } \\
- \text { artisan }\end{array}$ & $\begin{array}{c}\text { (ii) } \\
\text { Artisan - } \\
\text { HDQ }\end{array}$ & $\begin{array}{c}\text { (iii) } \\
\text { Zamindar } \\
- \text { HDQ }\end{array}$ \\
\hline \multirow{2}{*}{$\begin{array}{l}\text { Grandfather- } \\
\text { father }\end{array}$} & 0.500 & 0.443 & 0.185 & 0.0571 & $0.2584^{* * *}$ & $0.3155^{* * *}$ \\
\hline & & & & 0.0690 & 0.0680 & 0.0560 \\
\hline \multirow[t]{2}{*}{ Father-son } & 0.808 & 0.700 & 0.605 & 0.1077 & 0.0953 & $0.2030^{* * *}$ \\
\hline & & & & 0.0770 & 0.0920 & 0.0640 \\
\hline
\end{tabular}

Note: Standard errors reported below the difference in means. ${ }^{* *}=1$ percent significance level.

Source: Sargodha Village and Household Survey (2007/08).

Two facts are immediately apparent. First, in each generational pair, the proportion of households that transition into some level of schooling increases with the household's position in the rural social hierarchy. That is, households belonging to the zamindar quom have the highest rate of transitioning into schooling at both instances of generational change: 50 percent of the zamindar households with unschooled grandfathers sent their sons to school and 80.8 percent of zamindar households with unschooled fathers sent their sons to school. On the other hand, of the three quoms, the historically depressed households have the lowest rate of accomplishing the schooling transition from one generation to the next.

Second, an increasing proportion of households over time make the schooling transition across all three social groups; this could be a result of supply-side government programs that have ensured better school provision in the villages of Sargodha (Table 6). We find that, across all three social groups, the proportion of previously unschooled households that started sending their members to school is higher for the father-son pair than for the grandfather-father pair. 
However, we do find that, in spite of increased school provision, education mobility remains sluggish at the bottom of the social ladder. Thus, households belonging to the historically depressed quoms have a significantly lower rate of schooling transition than the zamindar households (the difference is statistically significant at 1 percent); a generation ago, their rate of schooling transition was even lower than that of the artisanal households (Table 5). As the quantile plots in the following section demonstrate, this gap in educational attainment raises interesting questions regarding households' demand for education and poses a serious challenge to the government's stated aim of universalizing education.

Table 6: School provision in 35 sample villages

\begin{tabular}{lccc}
\hline Time period & $\begin{array}{c}\text { No. of private } \\
\text { schools }\end{array}$ & $\begin{array}{c}\text { No. of public } \\
\text { schools }\end{array}$ & $\begin{array}{c}\text { No. of villages without a } \\
\text { school }\end{array}$ \\
\hline-1950 & 0 & 8 & 27 \\
$1951-70$ & 0 & 36 & 8 \\
$1971-90$ & 0 & 69 & 1 \\
$1991-$ & 15 & 76 & 1 \\
\hline
\end{tabular}

Source: National Education Census, 2005.

Table 7, which regresses years of schooling on generational dummies for the historically depressed and the nondepressed (zamindar and artisan) quoms separately, gives a sense of the magnitude of the challenge. It shows that the mean level of three years of schooling achieved by historically depressed quoms in the current generation is the level achieved by the nondepressed quoms a generation earlier. Put another way, the sons' generation of the historically depressed households has an educational attainment that was achieved by the father's generation in the nondepressed social groups. This suggests that, in rural Sargodha, historically depressed households have fallen a generation behind in terms of educational attainment. 


\section{Table 7: Education mobility: Historically depressed versus nondepressed quoms}

\begin{tabular}{lll}
\hline $\begin{array}{l}\text { Dependent variable: } \\
\text { Years of schooling }\end{array}$ & $\begin{array}{c}\text { Nondepressed (zamindar } \\
\text { and artisan) quoms }\end{array}$ & $\begin{array}{c}\text { Historically } \\
\text { depressed quom }\end{array}$ \\
\hline Current generation, $\mathrm{t}=3$ & $6.77^{* * * *}$ & $2.92^{* * * *}$ \\
Father's generation, $\mathrm{t}=2$ & $(31.3)$ & $(7.53)$ \\
& $3.43^{* * *}$ & 0.59 \\
Constant & $(15.8)$ & $(1.52)$ \\
& $0.70^{* * *}$ & 0.00 \\
Household fixed effects & $(4.59)$ & $(0.00)$ \\
Model F-statistic & 489.7 & Yes \\
$\mathrm{N}$ & 1284 & 31.7 \\
\hline
\end{tabular}

Note: ${ }^{* * *}=1$ percent significance level; t-statistics reported in parentheses. We control for household fixed effects.

Source: Sargodha Village and Household Survey $(2007 / 08)$.

\section{Evidence from Quantile/Mean Plots}

Next we revert to the variable capturing the detailed educational attainment, i.e., years of schooling, to unmask any heterogeneity in mobility within the different social groups. Unlike in Section 3, we do not focus here on the mean educational attainment in each generation and/or quom. Instead, we capture the heterogeneity in outcomes by calculating different percentiles of the education distribution and tracking their progression over time. The resulting quantile plots reveal interesting patterns that reinforce our earlier findings on educational mobility and help put them in starker relief.

However, before plotting the quantiles within each quom, Figure 1 plots the mean educational attainment for each generation and quom. This serves to reinforce the earlier finding that the different quoms have different educational outcome profiles and, moreover, that these differences are not closing over time. Therefore, while it is the case that zamindar quom households continue to be more educated than the other two classes and the mean educational attainment has increased for all three groups, the gap in their mean educational attainment has increased over time. 


\section{Figure 1: Average educational attainment over generations, by quom}

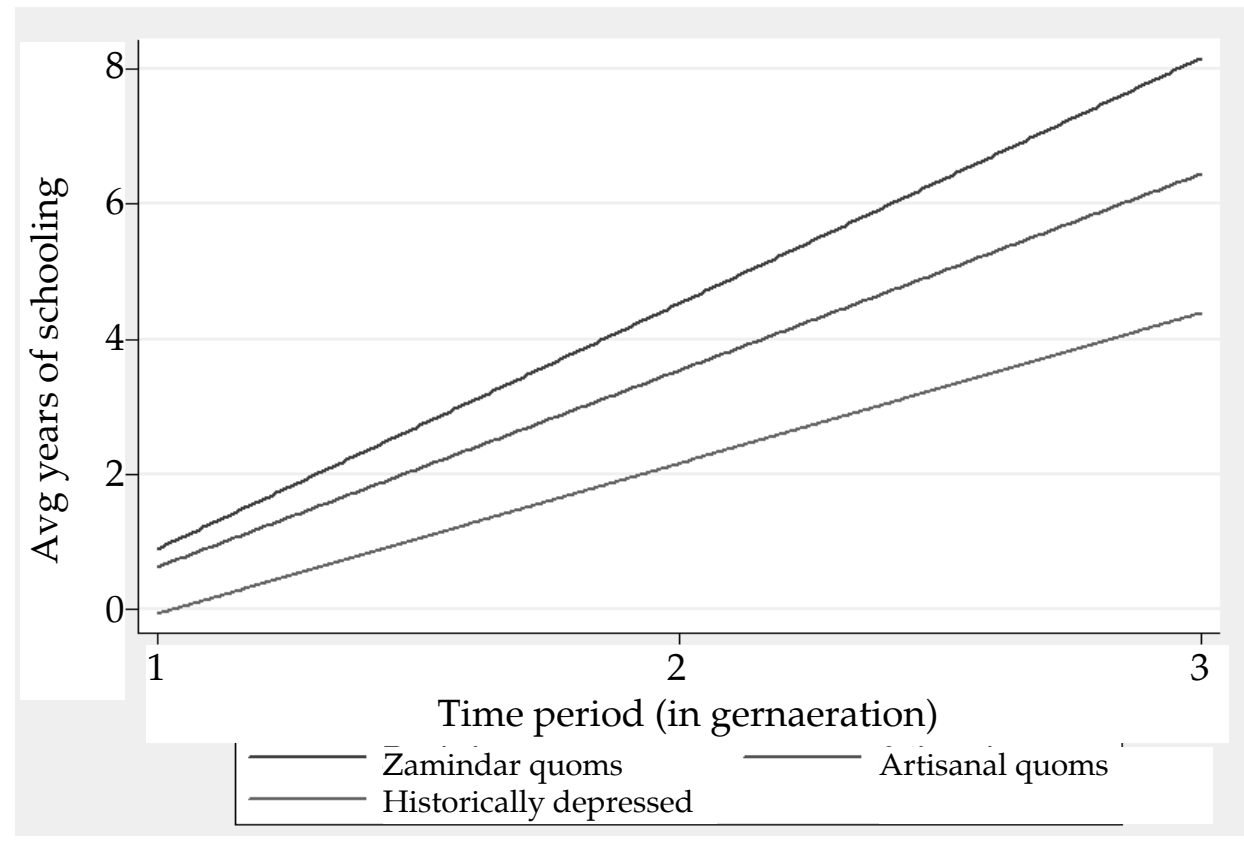

Note: The figure plots the average educational attainment against (the generational) time period for each of the three socioeconomic groups; $t=3$ refers to the current generation, $t$ $=2$ refers to the father's generation, and $\mathrm{t}=1$ is the grandfather's generation.

This divergence in educational attainment is interesting and we are not aware of any prior work that attempts to quantify or explain such a phenomenon. This may partly be explained by the fact that information on a household's quom is not collected in the Population Census or other standard large household surveys.

Next, we present a set of quantile plots in order to show that there is tremendous heterogeneity in educational attainment within the different quoms. To see this, for each quom, we plot and track five different percentiles of education distribution at each point in time. Three of these percentiles (the 35th, median, and 75th) lie close to the center of the distribution while the 25th percentile captures the bottom tail and the 90th percentile captures the top tail of the distribution. Figure 2 plots the quantiles for households belonging to the historically zamindar quom. 


\section{Figure 2: Quantile plots for educational attainment, by generation (historically zamindar quom)}

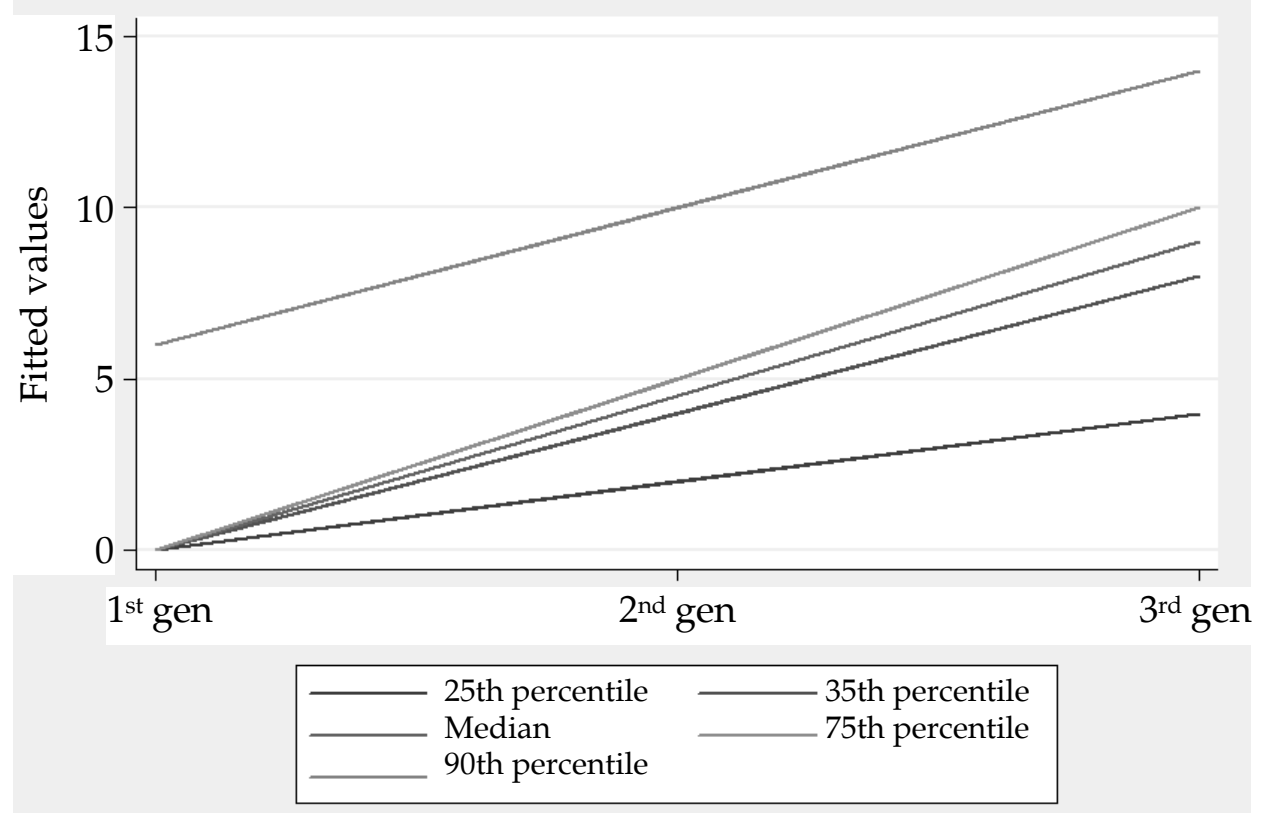

As shown by the graph above, one finds very different outcomes depending on which part of the education distribution one looks at. There is a slight overall increase in the dispersion of the education distribution as we move along the $x$-axis. There is no evidence of convergence between the 25th and 90th percentiles even though schooling levels are increasing in both percentiles. People in the middle have all increased their educational attainment over the years at the rate of about five years per generation though, even after three generations, the educational attainment has barely reached matriculation.

In contrast, Figures 3 and 4 show that, over the same period of time, a significant proportion of the households belonging to the historically landless social groups show zero educational mobility. 


\section{Figure 3: Quantile plots for educational attainment, by generation (artisans)}

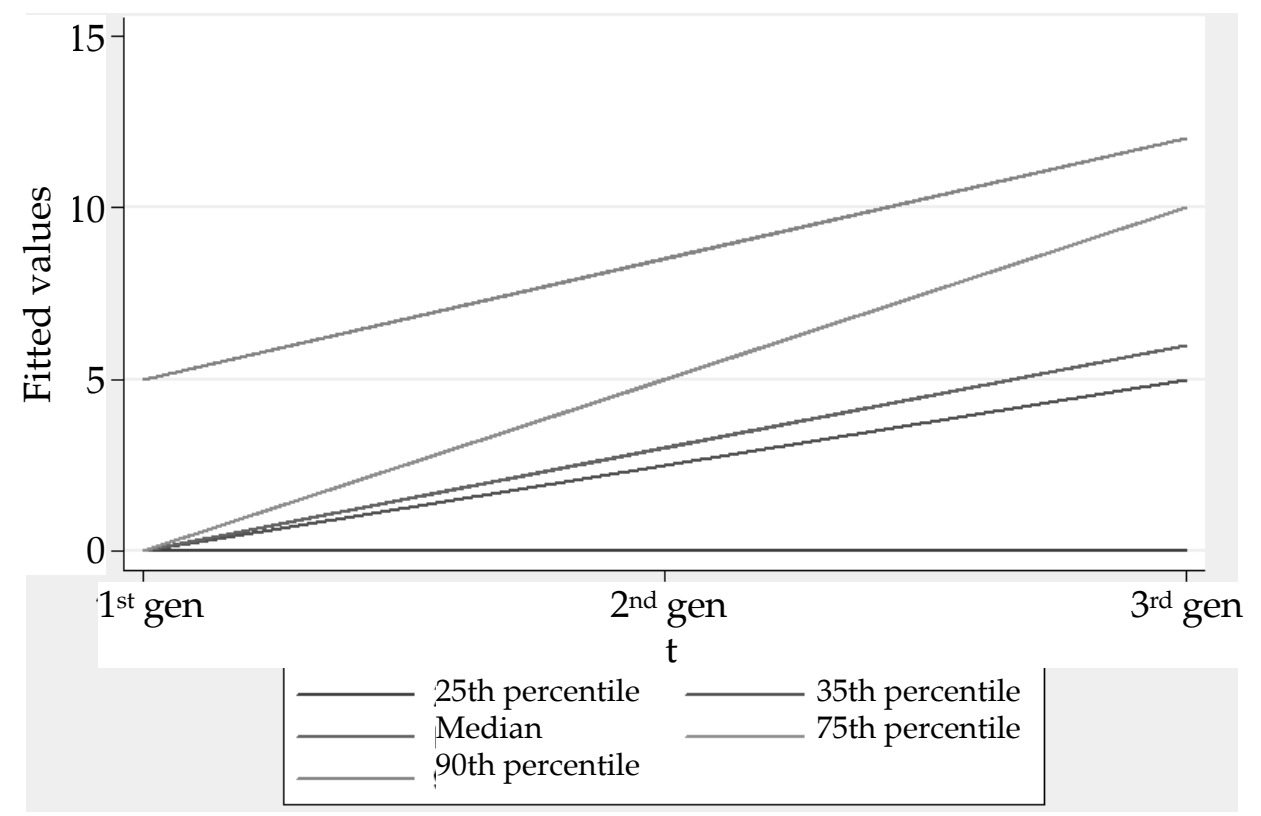

Even though the most educated households in these two quoms include males who have reached matriculation level or attained higher education, at least 25 percent of all artisan households and 35 percent of all historically depressed quom households still have males with zero years of schooling. Given that a decline in educational attainment from one generation to the next is less likely, a flat line for the 25th or 35th percentile indicates that there are households for whom there has been zero change in educational attainment over time and, hence, limited/zero upward mobility.

These "flatliners," who belong to the nonpropertied quoms, present the greatest challenge to fulfilling the objective set by Article 25-A of the Constitution. What is extremely worrying is that flatlining as a behavioral phenomenon is evident in the context of villages that have access to government schools. To achieve the goals set by 25-A, it is imperative that policymakers design policy interventions after rigorously analyzing the low demand for education in this group of households. 


\section{Figure 4: Quantile plots for educational attainment, by generation (historically depressed quoms)}

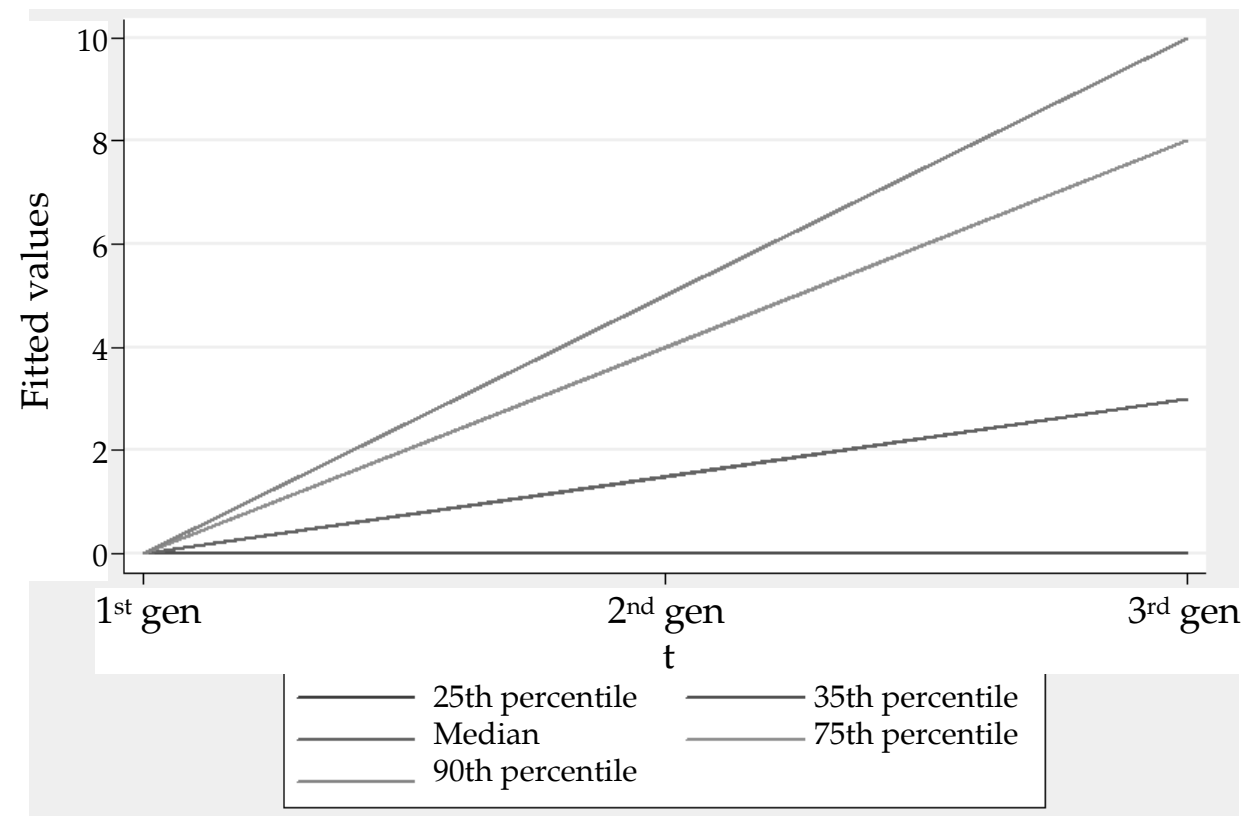

\section{Conclusions}

This paper has measured the extent of intergenerational persistence in educational mobility across propertied and nonpropertied quom groups in rural Sargodha in central Punjab. The analysis is based on a rich primary dataset constructed by the authors that collates information on three generations of families belonging to three quoms that historically comprised the hierarchy of village society in the district. The historical quom status of households is determined by carefully triangulating self-reported survey data with information contained in colonial village inspection reports and through community focus groups and interviews with village elders. The data allows us to create a unique father-son matched dataset for two successive generational pairs that is not restricted to the co-residence condition and, hence, is not subject to the selection bias that exists in most developing country studies on this issue.

We have found evidence of increasing intergenerational mobility in educational attainment across three generations of rural males in the district. The average persistence coefficient declines from 0.875 for the grandfather-father pair to 0.413 for the father-son pair. However, we have found significant differences in the degree of intergenerational mobility 
across quoms: the historically nonpropertied groups experience far less long-run mobility in educational attainment than the propertied groups. This indicates the worsening long-run equality of opportunities among these groups, implying that the agrarian transformation in the district has resulted in a lopsided rise in fortunes.

The intergenerational mobility coefficient among the propertied group in Sargodha is much higher than that reported for higher castes in India; the coefficients for the nonpropertied groups in the district are worse than those for Scheduled Castes in India. This suggests that long-run inequality in opportunities in the district is worse than that found across the border.

The proportion of households that transition into some level of schooling increases with the household's historical position in the rural social hierarchy. While impressive gains have been made by the propertied in terms of school transitions, households at the bottom of the historical social hierarchy continue to have extremely low rates of transition to school in spite of increased provision of schools in the district's villages. The outcome is that households belonging to the historically depressed quom have fallen a generation behind in terms of educational attainment compared to nondepressed quom households. This is in stark contrast to the finding for India that "there has been an improvement in mobility across social groups, especially at the lower end of the education distribution" (Azam \& Bhatt, 2012).

Finally, there is tremendous heterogeneity in educational attainment within the different quom groups. What is cause for serious concern is that artisan households in the $25^{\text {th }}$ percentile and the historically depressed quom households in the $35^{\text {th }}$ percentile of the distribution of educational attainment have had zero change in educational attainment across three generations. In our view, these "flatliners," who belong to the nonpropertied quoms, present the greatest challenge to meeting the objective set by Article 25-A of the Constitution. The fact that this is occurring in villages with schools suggests that it is these households' demand for education that is the most serious challenge to the government's stated aim of universalizing education. It seems that it will not be possible to design effective intervention tools to universalize education without understanding the channels underlying education demand failure among historically nonpropertied households. 


\section{References}

Agnihotri, I. (1996). Ecology, land use and colonization: The canal colonies of Punjab. Indian Economic and Social History Review, 33(1), 37-58.

Ahmad, S. (1977). Class and power in a Punjabi village. New York, NY: Monthly Review Press.

Ali, I. (1988). The Punjab under imperialism, 1885-1947. Princeton, NJ: Princeton University Press.

Arif, G. M. (2003). Poverty dynamics in Pakistan: Evidence from the twopanel household survey. In Pakistan human condition report 2003. Islamabad, Pakistan: Center for Research on Poverty Reduction and Income Distribution.

Arif, G. M. (2006). Poverty, economic growth and inequality: A review of Pakistan's poverty literature (Background Paper No. 1 for the Pakistan Poverty Assessment Update). Islamabad, Pakistan: Asian Development Bank.

Azam, M., \& Bhatt, V. (2012). Like father, like son? Intergenerational education mobility in India (Discussion Paper No. 6549). Bonn, Germany: Institute for the Study of Labor.

Banerjee, A. V., \& Duflo, E. (2003). Inequality and growth: What can the data say? Journal of Economic Growth, 8(3), 267-299.

Bayley, S. (2001). Caste, society and politics in India from the eighteenth century to the modern age. Cambridge, UK: Cambridge University Press.

Black, S., \& Devereux, P. (2011). Recent developments in intergenerational mobility. In O. Ashenfelter \& D. Card (Eds.), Handbook of labor economics (4B, chap. 16, pp. 1487-1541). Amsterdam: Elsevier.

The Constitution of the Islamic Republic of Pakistan. (1973). Retrieved 9 September 2013, from http://punjablaws.punjab.gov.pk/public/ dr/CONSTITUTION OF PAKISTAN.doc.pdf 
Hnatkovska, V., Lahiri, A., \& Paul, S. B. (2012). Breaking the caste barrier: Intergenerational mobility in India. Unpublished manuscript, University of British Columbia, Canada.

Jalan, J., \& Murgai, R. (2008, December). Intergenerational mobility in education in India. Paper presented at the $5^{\text {th }}$ Annual Conference of the Indian Statistical Institute, New Delhi, India.

Leigh, M. S. (1917). Gazetteer of the Shahpur district, 1917. Lahore, India: Government Printing Panjab.

Macnabb, A. C. (1934). Gazetteer of the Shahpur district, 1934. Lahore, India: Government Printing Panjab.

Maitra, P., \& Sharma, A. (2009, December). Parents and children: Education across generations in India. Paper presented at the $6^{\text {th }}$ Annual Conference of the Indian Statistical Institute, New Delhi, India.

Munshi, K., \& Rosenzweig, M. (2009). Why is mobility in India so low? Social insurance, inequality, and growth (Working Paper No. 14850). Cambridge, MA: National Bureau of Economic Research.

Nelson, M. (2002). Land, law and the logic of local politics in the Punjab, 18491999. Doctoral dissertation, Columbia University, NY.

Pray, C. E. (1984). Accuracy of official agricultural statistics and the sources of growth in the Punjab, 1907-1947. Indian Economic and Social History Review, 21(1), 312-333.

Rosenzweig, M. R., \& Munshi, K. (2006). Traditional institutions meet the modern world: Caste, gender and schooling choice in a globalizing economy. American Economic Review, 96(4), 1225-1252.

Rouse, S. J. (1988). Agrarian transformation in a Punjabi village: Structural change and its consequences. Doctoral dissertation, University of Wisconsin-Madison, WI.

Wace, F. B. (1933). The Punjab colony manual: Lower Jhelum colony conditions and forms. Lahore, India: Panjab Printing Company.

Wilson, J. (1897). Gazetteer of the Shahpur district, 1897. Lahore, India: Government Printing Panjab (Repr. 1994, Lahore, Pakistan: Sange-Meel). 